\title{
Overuse of Chest CT in Patients With Stage I and II Breast Cancer: An Opportunity to Increase Guidelines Compliance at an NCCN Member Institution
}

\author{
Barbara Dull, MD; Andrew Linkugel, BA; Julie A. Margenthaler, MD; and Amy E. Cyr, MD
}

\begin{abstract}
Background: The NCCN Clinical Practice Guidelines in Oncology (NCCN Guidelines) recommend that patients with clinical stage I/II breast cancer undergo advanced imaging for staging only when symptomatic. Regardless, many asymptomatic patients undergo chest CT. The goal of this study was to assess the use and results of chest CT in these patients at an NCCN Member Institution. Methods: Patients with breast cancer diagnosed between 1998 and 2012 were identified in a prospectively maintained database. All patients with clinical stage I/ II disease who did not receive neoadjuvant chemotherapy were included. Data collected included demographics, tumor size, node status, chest CT within 6 months of diagnosis, imaging findings, need for additional workup, and identification of metastatic disease. Appropriate statistical tests were used for analysis. Results: From 1998 to 2012, 3,321 patients were diagnosed with early-stage breast cancer. Of these, $2,062(62.1 \%)$ had clinical stage I breast cancer at diagnosis and 1,259 (37.9\%) had stage II; 227 patients (11\%) with stage I and 456 (36.2\%) with stage II breast cancer received staging chest CT. Of patients undergoing CT, $184(26.9 \%)$ were found to have pulmonary nodules, which measured $\leq 5 \mathrm{~mm}$ for 128 patients $(69.6 \%), 5$ to $10 \mathrm{~mm}$ for 46 patients $(25.0 \%), 11$ to $20 \mathrm{~mm}$ for 6 patients (3.2\%), and $\geq 20 \mathrm{~mm}$ for 4 patients (2.2\%). Patients undergoing chest CT for staging subsequently underwent a mean of 2.34 (range, $0-16)$ additional CTs in followup. Of all patients undergoing chest CT for staging, only $9(1.3 \%)$ were ultimately diagnosed with pulmonary metastases at an average of 25 months (range, 0-97) after initial staging chest CT. Conclusions: A significant percentage of patients with stage I/II breast cancer underwent unnecessary chest CT as part of their initial workup. Nearly one-third of these patients were found to have pulmonary nodules, but only $1.3 \%$ were ever diagnosed with pulmonary metastases. Adherence to NCCN Guidelines will reduce the excessive use of CT chest imaging.
\end{abstract}

J Natl Compr Canc Netw 2017;15(6):783-789 doi:10.6004/jncen.2017.0104

\section{Background}

An estimated 246,600 women were diagnosed with breast cancer in the United States in 2016, with most having stage I or II disease. ${ }^{1}$ According to the AJCC, stage I and II breast cancers are those with tumors $<5 \mathrm{~cm}$ in diameter and that have minimal or no disease in the ipsilateral axillary lymph nodes. ${ }^{2}$ If the cancer has spread to lymph nodes, it is limited to 1 to 3 nodes. For patients diagnosed with stage I and II breast cancer, 5 -year survival rates are as high as $85 \%$ to $99 \%{ }^{1}$

From the Division of General Surgery, Section of Endocrine and Oncologic Surgery, Washington University, St. Louis, Missouri.

Submitted September 24, 2016; accepted for publication January 13, 2017.

The authors have disclosed that they have no financial interests,

arrangements, affiliations, or commercial interests with the manufacturers of any products discussed in this article or their competitors. Mr. Linkugel received funding support for this study from the DeNardo Education and Research Foundation Grant.
In this group of patients, the NCCN Clinical Practice Guidelines in Oncology (NCCN Guidelines) recommend standard imaging with diagnostic bilateral mammography and ultrasound; breast MRI may also be used. $^{3}$ Additional staging studies are only recommended if signs or symptoms of possible distant metastases are present. Diagnostic chest CT is recommended if pulmonary symptoms are present at diagnosis.

Several other societies have published similar guidelines. In 2012, ASCO addressed the rising costs

Author contributions: Study design: Margenthaler, Cyr. Data acquisition: Dull, Linkugel. Data analysis: Dull, Cyr. Drafting of manuscript: Margenthaler, Dull, Cyr.

The abstract was presented as a poster at the 2015 Society of Surgical Oncology Clinical Congress; March 2-5, 2015; Boston, MA.

Correspondence: Amy E. Cyr, MD, Washington University School of Medicine, Department of Surgery, CB 8109, 660 South Euclid Avenue, St. Louis, MO 63110. E-mail: cyra@wudosis.wustl.edu 
of cancer care by identifying 5 areas in which care could be improved and costs reduced. ${ }^{4}$ They identified the routine use of PET imaging, CT scans, and radionuclide bone scans for staging in patients identified with ductal carcinoma in situ and stage I and II breast cancer as not only costly but also potentially harmful due to the need for additional invasive procedures, overtreatment, and unnecessary radiation exposure. Recommendations from the European Society for Medical Oncology (ESMO) and Britain's National Institute for Health and Clinical Excellence (NICE) echo these guidelines for patients with early-stage breast cancer. ${ }^{5,6}$

The NCCN recommendations are based on studies demonstrating the low probability of finding distant metastases in patients with early-stage breast cancer. In a 2005 study, all patients with early-stage breast cancer underwent chest radiography and only 0.93\% were found to have lung metastases. ${ }^{7}$ In 2008 , Lee et $\mathrm{al}^{8}$ published their results of a retrospective review of patients with early-stage breast cancer undergoing staging chest CTs, reporting that, in this group of patients, subcentimeter indeterminate pulmonary nodules were unlikely to represent metastatic disease. There is now a growing body of evidence supporting the low rate of distant metastases in patients with early-stage breast cancer. ${ }^{9-16}$ For example, in a study of 2,612 patients with breast cancer in the United Kingdom, metastases were found in no patients with stage 0 or I disease and only $0.3 \%$ of patients with stage II breast cancer. ${ }^{10}$ The number of false-positives in this study was $3.8 \%$, leading to additional imaging and invasive testing. In a systemic review published in 2012, Brennan and Houssami ${ }^{11}$ confirmed the low prevalence of distant metastases in patients with asymptomatic stage I and II breast cancer $(0.2 \%$ and $1.2 \%$, respectively) and determined that routine staging studies were unnecessary in this patient population.

Even with these numerous guidelines and recommendations, staging studies are routinely performed in patients with stage I and II breast cancer. Despite NCCN recommendations, many patients with asymptomatic early-stage breast cancer continue to undergo chest CT as part of their initial evaluation. The goal of this study was to assess the use of chest CT in patients with asymptomatic clinical stage I and II breast cancer at an NCCN Member Institution and the outcomes of that testing.

\section{Methods}

A prospectively maintained institutional database of all surgical patients with breast cancer was queried after approval from the Washington University Institutional Review Board. A retrospective chart review was then undertaken of all patients with clinical stage I and II breast cancer as defined by the 7th edition of the AJCC Cancer Staging Manual who were diagnosed from 1998 to 2012. Tumor size at diagnosis was recorded based on imaging and clinical examination findings. Similarly, nodal involvement was documented based on examination and imaging findings, as well as results of fine-needle aspiration or biopsy, if performed. Patients who underwent neoadjuvant chemotherapy were excluded from this study because of inconsistencies in accurately determining stage at diagnosis. Patients with a recurrent breast cancer, with multiple concurrent cancers, and under routine surveillance for other nonbreast malignancies were also excluded from the study. Additionally, patients were excluded if they underwent a chest CT due to documented pulmonary symptoms.

Of the patients included in the study, charts were reviewed for the use of chest CT within 6 months of diagnosis. The 6 -month period was chosen in order to exclude chest CTs that may have been performed for surveillance or due to tumor recurrence. For the patients undergoing chest CTs within 6 months of diagnosis, imaging findings and need for additional workup were recorded. Follow-up imaging and biopsy results, if performed, were also reviewed. Subsequent findings of pulmonary metastases were recorded, as were demographic data and tumor characteristics, such as pathology size and tumor marker profile.

Statistical analysis was performed using Fisher exact test and Student unpaired $t$-test, with a $P$ value $<.05$ being considered statistically significant.

\section{Results}

During the 14-year study period, 3,321 patients were diagnosed with early-stage breast cancer and had primary surgical treatment. Of these patients, 2,062 $(62.1 \%)$ had clinical stage I breast cancer and 1,259 (37.9\%) had stage II on initial evaluation. Within 6 months of initial diagnosis, 227 patients $(11 \%)$ with stage I breast cancer and $456(36.2 \%)$ with stage II had a staging chest CT to evaluate for pulmonary metastases (Table 1). Of the 227 patients with stage 
I breast cancer, 51 (22.5\%) were found to have pulmonary nodules; $>60 \%$ of patients in this group had nodules measuring $\leq 5 \mathrm{~mm}, 35.3 \%$ were found to have nodules measuring 5 to $10 \mathrm{~mm}$, and one patient was found to have a nodule measuring $\geq 20 \mathrm{~mm}$. Similar results were found in the patients with stage II breast cancer: 96 (72.2\%) were found to have nodules measuring $\leq 5 \mathrm{~mm}, 28(20.6 \%)$ had nodules measuring 5 to $10 \mathrm{~mm}, 6(4.5 \%)$ had nodules measuring 10 to $20 \mathrm{~mm}$, and $3(2.2 \%)$ patients were found to have nodules $\geq 20 \mathrm{~mm}$.

The finding of a pulmonary nodule on a staging chest CT led to an average of 2.34 additional followup chest CTs (Table 1). The range of follow-up chest CTs varied widely, with many patients undergoing no additional imaging, whereas others were followed for years with up to 16 additional chest CTs. Of the 51 patients with stage I breast cancer found to have pulmonary nodules, 15 (29.4\%) underwent no additional imaging; $42.9 \%$ of those with stage II with pulmonary nodules had no follow-up chest CTs.

In comparing the 2,638 patients who did not have staging chest CTs versus those who did undergo a scan, multiple differences were noted in patient and tumor characteristics (Table 2). Patients who underwent a staging chest CT were younger than those who did not undergo imaging. Patients with clinical stage II breast cancer were more likely to undergo a staging chest CT. Of the 2,420 patients found to have T1 tumors, only 355 (14.7\%) underwent a staging chest CT compared with 36\% (306/852) of

\begin{tabular}{|c|c|c|}
\hline & Stage I & Stage II \\
\hline Total patients & 2,062 & 1,259 \\
\hline Staging $\mathrm{CT}$ chest performed & $227(11 \%)$ & $436(36.2 \%)$ \\
\hline $\begin{array}{l}\text { Patients with pulmonary } \\
\text { nodules }\end{array}$ & $51(22.5 \%)$ & $133(29.2 \%)$ \\
\hline \multicolumn{3}{|l|}{ Size of nodules identified on CT } \\
\hline$\leq 5 \mathrm{~mm}$ & $32(62.7 \%)$ & $96(72.2 \%)$ \\
\hline $5-10 \mathrm{~mm}$ & $18(35.3 \%)$ & $28(21.0 \%)$ \\
\hline $10-20 \mathrm{~mm}$ & $0(0 \%)$ & $6(4.5 \%)$ \\
\hline$\geq 20 \mathrm{~mm}$ & $1(2 \%)$ & $3(2.3 \%)$ \\
\hline $\begin{array}{l}\text { Patients ultimately diagnosed } \\
\text { with pulmonary metastases }\end{array}$ & $2(0.9 \%)$ & $7(1.5 \%)$ \\
\hline $\begin{array}{l}\text { Mean number of follow-up } \\
\text { CTs (range) }\end{array}$ & $2.33(0-10)$ & $2.35(0-16)$ \\
\hline $\begin{array}{l}\text { Patients without follow-up } \\
\text { CTs, n }\end{array}$ & $15(29.4 \%)$ & $57(42.9 \%)$ \\
\hline
\end{tabular}

those with T2 tumors and 44.9\% (22/49) of those with T3 tumors. Similarly, patients found to have nodal metastases were also significantly more likely to undergo a staging chest CT than those who either had no nodal metastases or N1mic disease $(P<.001$ for all). Patients who were staged were also more likely to have estrogen receptor (ER)-negative, progesterone receptor (PR)-negative, and HER2amplified tumors $(P<.01$ for all $)$.

Ultimately, 9 patients $(1.3 \%)$ who underwent a staging chest CT were found to have or developed pulmonary metastases (Table 3). Three patients

\begin{tabular}{|c|c|c|c|c|c|}
\hline & \multicolumn{2}{|c|}{$\begin{array}{c}\text { No Staging } \\
\text { Chest CT } \\
\text { Performed } \\
(n=2,638 ; \\
79 \%)\end{array}$} & \multicolumn{2}{|c|}{$\begin{array}{l}\text { Staging Chest } \\
\text { CT Performed } \\
(n=683 ; 21 \%)\end{array}$} & \multirow{2}{*}{$\begin{array}{c}P \\
\text { Value }\end{array}$} \\
\hline & $\mathrm{n}$ & $\%$ & $\mathrm{n}$ & $\%$ & \\
\hline \multicolumn{6}{|c|}{ Age at diagnosis, y } \\
\hline$<50$ & 607 & $23 \%$ & 247 & $36 \%$ & \multirow[t]{2}{*}{$<.001$} \\
\hline$\geq 50$ & 2,031 & $77 \%$ & 436 & $64 \%$ & \\
\hline \multicolumn{6}{|l|}{ Clinical stage } \\
\hline I & 1,835 & $70 \%$ & 227 & $33 \%$ & \multirow[t]{2}{*}{$<.001$} \\
\hline II & 803 & $30 \%$ & 456 & $67 \%$ & \\
\hline \multicolumn{6}{|l|}{ Tumor size } \\
\hline $\mathrm{T} 1$ & 2,065 & $78 \%$ & 355 & $52 \%$ & \multirow[t]{3}{*}{$<.001$} \\
\hline $\mathrm{T} 2$ & 546 & $21 \%$ & 306 & $45 \%$ & \\
\hline $\mathrm{T3}$ & 27 & $1 \%$ & 22 & $3 \%$ & \\
\hline \multicolumn{6}{|l|}{ Nodal status } \\
\hline $\begin{array}{l}\text { No } \\
\text { (including } \\
\text { N1mic) }\end{array}$ & 2,222 & $84 \%$ & 438 & $64 \%$ & \multirow[t]{3}{*}{$<.001$} \\
\hline N1 & 621 & $24 \%$ & 241 & $35 \%$ & \\
\hline Unknown & 65 & $2 \%$ & 4 & $1 \%$ & \\
\hline \multicolumn{6}{|l|}{ ER status } \\
\hline Positive & 2,068 & $78 \%$ & 457 & $67 \%$ & \multirow[t]{2}{*}{$<.001$} \\
\hline Negative & 489 & $19 \%$ & 214 & $31 \%$ & \\
\hline Unknown & 81 & $3 \%$ & 12 & $2 \%$ & \\
\hline \multicolumn{6}{|l|}{ PR status } \\
\hline Positive & 1,788 & $68 \%$ & 410 & $60 \%$ & \multirow[t]{2}{*}{$<.001$} \\
\hline Negative & 759 & $29 \%$ & 259 & $38 \%$ & \\
\hline Unknown & 91 & $3 \%$ & 14 & $2 \%$ & \\
\hline \multicolumn{6}{|l|}{ HER2 status } \\
\hline Positive & 428 & $16 \%$ & 151 & $22 \%$ & \multirow[t]{2}{*}{$<.01$} \\
\hline Negative & 1,447 & $55 \%$ & 393 & $58 \%$ & \\
\hline Unknown & 763 & $29 \%$ & 139 & $20 \%$ & \\
\hline
\end{tabular}

Abbreviations: ER, estrogen receptor; PR, progesterone receptor. 
were diagnosed with pulmonary metastases at initial staging chest CT and were upstaged to a stage IV breast cancer. Of the remaining 6 patients, 3 continued to undergo routine follow-up chest CTs and were eventually diagnosed with metastases (range, 9-91 months), whereas the other 3 ultimately diagnosed with pulmonary metastases underwent eventual chest CT due to symptoms such as chest pain or shortness of breath (range, 7-61 months).

When patients with incidental pulmonary nodules were compared with those with pulmonary metastases, no differences were seen between the groups (Table 4). Although 8 patients (89\%) with pulmonary metastases were aged $>50$ years at the time of their breast cancer diagnosis compared with $68 \%$ of those with incidental pulmonary nodules, this did not reach statistical significance. Similarly, no differences were seen in clinical stage at diagnosis, tumor size, and nodal status between the groups. Patients found to have pulmonary metastases did not have higher rates of ER and PR negativity or HER2 amplification when compared with those without pulmonary metastases.

\begin{tabular}{|c|c|c|c|c|}
\hline Patient & $\begin{array}{l}\text { Age at } \\
\text { Breast } \\
\text { Cancer } \\
\text { Diagnosis }\end{array}$ & $\begin{array}{l}\text { Initial } \\
\text { Stage }\end{array}$ & $\begin{array}{c}\text { Time to } \\
\text { Diagnosis of } \\
\text { Pulmonary } \\
\text { Metastases } \\
\text { (mo) }\end{array}$ & $\begin{array}{l}\text { Reason for } \\
\text { Chest CT }\end{array}$ \\
\hline 1 & 42 & IIA & 31 & $\begin{array}{l}\text { Routine } \\
\text { follow-up }\end{array}$ \\
\hline 2 & 56 & IIA & 91 & $\begin{array}{l}\text { Routine } \\
\text { follow-up }\end{array}$ \\
\hline 3 & 60 & IA & 7 & $\begin{array}{l}\text { Chest pain \& } \\
\text { SOB }\end{array}$ \\
\hline 4 & 61 & IIB & 21 & Chest pain \\
\hline 5 & 70 & IIA & 61 & SOB \\
\hline 6 & 71 & IIA & 0 & $\begin{array}{l}\text { Initial staging } \\
\text { chest CT }\end{array}$ \\
\hline 7 & 73 & IIA & 0 & $\begin{array}{l}\text { Initial staging } \\
\text { chest CT }\end{array}$ \\
\hline 8 & 79 & IIB & 0 & $\begin{array}{l}\text { Initial staging } \\
\text { chest CT }\end{array}$ \\
\hline 9 & 80 & IA & 9 & $\begin{array}{l}\text { Routine } \\
\text { follow-up }\end{array}$ \\
\hline
\end{tabular}

Abbreviation: SOB, shortness of breath.

\section{Discussion}

Our findings demonstrate that the likelihood of finding pulmonary metastases in patients with earlystage breast cancer is unlikely, but false-positives are frequent and lead to additional unnecessary imaging. This has been corroborated by other retrospective studies. ${ }^{8,11-16} \mathrm{Kim}$ et $\mathrm{al}^{12}$ published their findings in 2011 of 1,703 patients with breast cancer who underwent routine staging chest CTs, and $15.6 \%$ were found to have abnormalities in either the lungs or the liver. True metastases were identified in $1.5 \%$ of all patients, with all but one metastasis being identified in patients with stage III disease. Studies of the utility of PET in evaluating patients with breast

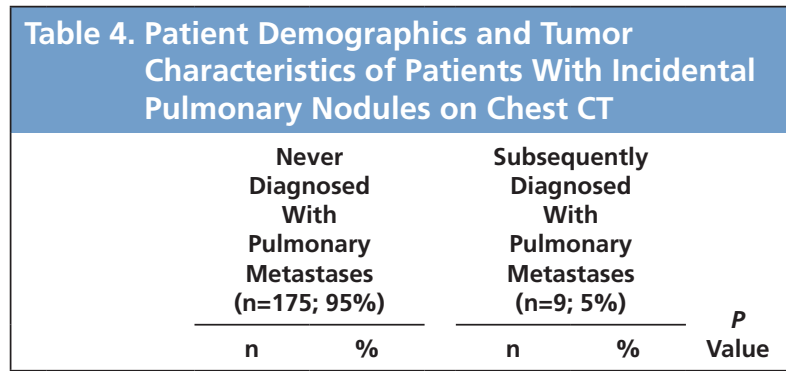

\begin{tabular}{|c|c|c|c|c|c|}
\hline \multicolumn{6}{|c|}{ Age at diagnosis } \\
\hline$<50$ & 56 & $32 \%$ & 1 & $11 \%$ & NS \\
\hline$\geq 50$ & 119 & $68 \%$ & 8 & $89 \%$ & NS \\
\hline \multicolumn{6}{|l|}{ Clinical stage } \\
\hline I & 49 & $28 \%$ & 2 & $22 \%$ & NS \\
\hline II & 126 & $72 \%$ & 7 & $78 \%$ & NS \\
\hline \multicolumn{6}{|l|}{ Tumor size } \\
\hline $\mathrm{T} 1$ & 90 & $51 \%$ & 3 & $33 \%$ & NS \\
\hline $\mathrm{T} 2$ & 82 & $47 \%$ & 6 & $67 \%$ & NS \\
\hline T3 & 3 & $2 \%$ & 0 & $0 \%$ & NS \\
\hline \multicolumn{6}{|l|}{ Nodal status } \\
\hline $\begin{array}{l}\text { No } \\
\text { (including } \\
\text { N1mic) }\end{array}$ & 92 & $53 \%$ & 6 & $67 \%$ & NS \\
\hline $\mathrm{N} 1$ & 83 & $47 \%$ & 3 & $33 \%$ & NS \\
\hline \multicolumn{6}{|l|}{ ER status } \\
\hline Positive & 124 & $71 \%$ & 5 & $56 \%$ & NS \\
\hline Negative & 51 & $29 \%$ & 4 & $44 \%$ & NS \\
\hline \multicolumn{6}{|l|}{ PR status } \\
\hline Positive & 109 & $62 \%$ & 4 & $44 \%$ & NS \\
\hline Negative & 66 & $38 \%$ & 5 & $56 \%$ & NS \\
\hline \multicolumn{6}{|l|}{ HER2 status } \\
\hline Positive & 39 & $22 \%$ & 3 & $33 \%$ & NS \\
\hline Negative & 136 & $78 \%$ & 6 & $67 \%$ & NS \\
\hline
\end{tabular}

Abbreviations: ER, estrogen receptor; NS, not significant; PR, progesterone receptor. 
cancer for distant metastases have also demonstrated similarly low rates of pulmonary metastases in those with early-stage disease. ${ }^{17,18}$ Data from the radiation oncology literature also support these findings. Investigators from Stanford evaluated the incidence of unsuspected abnormalities on radiation treatmentplanning CT scans in patients with breast cancer and detected 4 incidental lung nodules in 153 patients (2.6\%) evaluated. ${ }^{19}$ On further follow-up, one lung nodule was due to tuberculosis and the remaining 3 were found to be old granulomatous disease. Further studies reviewing both non-contrast-enhanced and contrast-enhanced CT treatment planning scans have demonstrated detection rates for pulmonary nodules ranging between $4 \%$ and $13 \%$, with few being clinically significant. ${ }^{20-22}$

In this study, we found that patients who underwent staging chest CTs were younger and more likely to have unfavorable tumor markers, and multiple other investigators have found similar results. ${ }^{14,15,23}$ Although a few studies have demonstrated that younger age at diagnosis and ER and PR negativity and HER2 amplification are risk factors for visceral metastases, ${ }^{24,25}$ our data do not support the need for routine chest imaging in this population. When the characteristics of the patients who were staged and found to have pulmonary metastases were evaluated against those with incidental pulmonary nodules detected, no difference was found in age or tumor marker status. In fact, age and tumor marker status are characteristics not addressed in the NCCN Guidelines for staging workup, and these data support that recommendation.

Other patient and tumor characteristics have been associated with the use of staging studies. Crivello et $\mathrm{al}^{15}$ used the SEER database to examine the records of $>67,000$ patients. In addition to age and ER negativity being associated with the use of imaging studies, they noted that use of breast MRI, lobular histology, and stage II disease versus stage I predicted for the use of CTs, PET scans, and bone scans. Our data and those of Crivello et $\mathrm{al}^{15}$ and other investigators reliably show that patients with a higher stage are more likely to undergo imaging studiesfor instance, stage II versus stage I, and stage IIB versus IIA ${ }^{15,16}$ — and there are some data to support this trend. Gerber et $\mathrm{al}^{13}$ retrospectively analyzed $>1,000$ patients with asymptomatic newly diagnosed breast cancer and found that the finding of metasta- ses was associated with increasing pathologic tumor size $(P<.001)$ and increased nodal burden $(P<.001) .{ }^{13}$ Other authors have published similar results. ${ }^{26,27}$

The rate of pulmonary nodule detection in this study was $27.7 \%$, which is higher than that reported in the radiation oncology literature, but consistent with other large-volume studies. 28,29 The high detection rate of incidental pulmonary nodules has led to recommendations for additional follow-up from the Fleischner Society and the American College of Chest Physicians. ${ }^{30,31}$ These guidelines are aimed at identifying patients with lung cancer and vary based on the size of the nodule identified and patient risk factors for lung cancer, but can be extrapolated to this patient population. These guidelines recommend that any patient at risk for cancer found to have a nodule of any size should undergo repeat imaging. Rates of follow-up imaging in the literature are low, reaching only 29\% to $34 \%$ in some studies. ${ }^{32-34}$ The rate of follow-up CTs in this study was $70.6 \%$ in patients with stage I breast cancer and $57.1 \%$ in those with stage II. Although the rate of follow-up in this study was higher than that reported in the lung cancer literature, not all patients imaged received the recommended follow-up, suggesting that the ordering physician deemed the nodules to be inconsequential.

Given the rate of follow-up imaging, the question arises as to why the initial staging CT was ordered. The ASCO Top 5 list was published to identify the increasing cost of healthcare spending and the costs of unnecessary testing. The 2009 ASCO Cost of Care Task Force found that the use of PET, $\mathrm{CT}$, and bone scan in staging patients with clinical stage I and II breast cancer lacks evidence and leads to harm through additional invasive procedures, overtreatment, radiation exposure, and misdiagnosis. ${ }^{4}$ After publication of the ASCO guidelines, Simos et $\mathrm{al}^{35}$ noted no reduction in staging imaging for patients with early-stage breast cancer. A follow-up study published in 2015 found that $82 \%$ of physicians treating patients with breast cancer were aware of the newly published guidelines, but that it had not influenced them to order less imaging. ${ }^{36} \mathrm{~A}$ meta-analysis by $\mathrm{Ca}$ bana et $\mathrm{al}^{37}$ evaluating physician barriers to adherence to published guidelines found the reasons behind this to be multifactorial. They cited lack of awareness, lack of agreement with guidelines, inertia of previous practice, and patient preferences as a few of the obstacles prohibiting physicians from following prac- 
Dull et al

tice guidelines. Simos et $\mathrm{a}^{138}$ evaluated patient perceptions regarding imaging for metastases via a questionnaire and found that $57.1 \%$ desired to have imaging performed if the chance of detecting metastases was $\leq 10 \%$ and $70.4 \%$ reported they would feel uncomfortable if their physician did not order imaging, regardless of guidelines. Improved patient education on the minimal benefits of staging studies may help decrease the ordering of these unnecessary tests.

This study had several limitations because it was based on a retrospective chart review, and therefore medical data may be missing or incomplete. For instance, patient smoking history is not recorded in the breast cancer database, but may have contributed to a higher incidence of pulmonary nodules being visualized. Because the Siteman Cancer Center is a tertiary referral center, not all patients choose to receive all of their care at this location; they may have received care and imaging at other institutions, and that information would not be included in our database. This study may also be affected by selection bias, because patients undergoing neoadjuvant therapy were excluded. These patients usually have more advanced disease and are more likely to have either ER-negative or PR-negative tumors or HER2-amplified tumors. Even for patients who received neoadjuvant systemic therapy, however, NCCN Guidelines recommend only that staging studies be considered for patients with clinical stage II disease or higher, with a footnote clarifying that "routine systemic staging is not indicated for early-stage breast cancer in the absence of symptoms." ${ }^{3}$ Additional bias may exist because the study cohort was identified in a surgical database, and therefore patients found to have metastasis at diagnosis may not have been referred to our clinic. However, routine use of staging studies is more likely to identify clinically insignificant findings or non-breast cancer findings than it is to identify metastatic disease, and therefore change the plan of treatment.

\section{Conclusions}

Despite its limitations, this study adds to the literature arguing against the routine use of staging chest CTs in patients with asymptomatic stage I and II breast cancer. Our study shows that although a large percentage of patients were found to have incidental pulmonary nodules, only $1.3 \%$ of all patients ultimately developed pulmonary metastases. Adherence to the NCCN Guidelines will not only spare patients unnecessary testing but, in an era of increasing healthcare costs, also curb excessive spending.

\section{Acknowledgments}

We would like to thank and acknowledge Kathy Lyons for maintaining and querying the surgical breast cancer database at Washington University.

\section{References}

1. Cancer Stat Facts: Female Breast Cancer. National Cancer Institute Surveillance, Epidemiology, and End Results Program Web site. Available at: http://seer.cancer.gov/statfacts/html/breast.html. Accessed September $10,2016$.

2. AJCC. Breast Cancer Staging. Available at: https://cancerstaging.org/ references-tools/quickreferences/Documents/BreastMedium.pdf. Accessed August 22, 2016.

3. Gradishar WJ, Anderson BO, Balassanian R, et al. NCCN Clinical Practice Guideline in Oncology, Breast Cancer, Version 2.2016. Accessed January 13,2017 . To view the most recent version of these guidelines, visit NCCN.org.

4. Schnipper LE, Smith TJ, Raghavan D, et al. American Society of Clinical Oncology identifies five key opportunities to improve care and reduce costs: the top five list for oncology. J Clin Oncol 2012;30:1715-1724.

5. Senkus E, Kyriakides S, Ohno S, et al. Primary breast cancer: ESMO Clinical Practice Guidelines for diagnosis, treatment and follow-up. Ann Oncol 2013;24(Suppl 6):vi7-23.

6. Breast cancer. National Institute for Health and Care Excellence Web site. Available at: https://www.nice.org.uk/guidance/qs12. Accessed September 10, 2016.

7. Puglisi F, Follador A, Minisini AM, et al. Baseline staging tests after a new diagnosis of breast cancer: further evidence of their limited indications. Ann Oncol 2005;16:263-266.

8. Lee B, Lim A, Lalvani A, et al. The clinical significance of radiologically detected silent pulmonary nodules in early breast cancer. Ann Oncol 2008;19:2001-2006.

9. Ravaioli A, Pasini G, Polselli A, et al. Staging of breast cancer: new recommended standard procedure. Breast Cancer Res Treat 2002;72:5360.

10. Barrett T, Bowden DJ, Greenberg DC, et al. Radiological staging in breast cancer: which asymptomatic patients to image and how. Br J Cancer 2009;101:1522-1528.

11. Brennan ME, Houssami N. Evaluation of the evidence on staging imaging for detection of asymptomatic distant metastases in newly diagnosed breast cancer. Breast 2012;21:112-123.

12. Kim H, Han W, Moon HG, et al. The value of preoperative staging chest computed tomography to detect asymptomatic lung and liver metastasis in patients with primary breast carcinoma. Breast Cancer Res Treat 2011;126:637-641.

13. Gerber B, Seitz E, Muller H, et al. Perioperative screening for metastatic disease is not indicated in patients with primary breast cancer and no clinical signs of tumor spread. Breast Cancer Res Treat 2003;82:29-37.

14. Makarov DV, Soulos PR, Gold HT, et al. Regional-level correlations in inappropriate imaging rates for prostate and breast cancers: potential implications for the Choosing Wisely campaign. JAMA Oncol 2015;1:185-194.

15. Crivello ML, Ruth K, Sigurdson ER, et al. Advanced imaging modalities in early stage breast cancer: preoperative use in the United States Medicare population. Ann Surg Oncol 2013;20:102-110. 
16. Kamal A, Zhang T, Power S, Marcom PK. Is advanced imaging in earlystage breast cancer ever warranted? Reconciling clinical judgment with common quality measures. J Natl Compr Canc Netw 2016;14:993-998.

17. Cermik TF, Mavi A, Basu S, et al. Impact of FDG PET on the preoperative staging of newly diagnosed breast cancer. Eur J Nucl Med Mol Imaging 2008;35:475-483.

18. Fuster D, Duch J, Paredes P, et al. Preoperative staging of large primary breast cancer with [18F]fluorodeoxyglucose positron emission tomography/ computed tomography compared with conventional imaging procedures. J Clin Oncol 2008;26:4746-4751.

19. Mehta VK, Goffinet DR. Unsuspected abnormalities noted on CT treatment-planning scans obtained for breast and chest wall irradiation. Int J Radiat Oncol Biol Phys 2001;49:723-725.

20. Nakamura N, Tsunoda $H$, Takahashi $O$, et al. Frequency and clinical significance of previously undetected incidental findings detected on computed tomography simulation scans for breast cancer patients. Int J Radiat Oncol Biol Phys 2012;84:602-605.

21. Rao $S$, Patel $A$, Levin $K$, et al. How often are previously undetected radiographic abnormalities detected at the time of CT simulation for breast cancer patients? Am J Clin Oncol 2010;33:262-264.

22. Kim MJ, Kim EK, Keum KC, et al. Treatment-planning CT scan for breast and chest-wall irradiation: how many unexpected abnormalities could we detect? Clin Imaging 2008;32:443-446.

23. Linkugel A, Margenthaler J, Dull B, et al. Staging studies have limited utility for newly diagnosed stage I-II breast cancer. J Surg Res 2015;196:3338.

24. Purushotham A, Shamil E, Cariati M, et al. Age at diagnosis and distant metastasis in breast cancer-a surprising inverse relationship. Eur J Cancer 2014;50:1697-1705.

25. Hung MH, Liu CY, Shiau CY, et al. Effect of age and biological subtype on the risk and timing of brain metastasis in breast cancer patients. PLoS One 2014;9:e89389.

26. Levon V, Alberini JL, Pierga JY, et al. The rate of distant metastases on FDG-PET/CT at initial staging of breast cancer: comparison between women younger and older than 40 years. J Nucl Med 2017;58:252-257.
27. Reidl CC, Slobod E, Jochelson M, et al. Retrospective analysis of 18F-FDG $\mathrm{PET} / \mathrm{CT}$ for staging asymptomatic breast cancer patients younger than 40 years. J Nucl Med 2014;55:1578-1583.

28. Gould MK, Tang T, Liu IA, et al. Recent trends in the identification of incidental pulmonary nodules. Am J Respir Crit Care Med 2015;192:12081214.

29. Rinaldi MF, Bartalena T, Giannelli G, et al. Incidental lung nodules on CT examinations of the abdomen: prevalence and reporting rates in the PACS era. Eur J Radiol 2010;74:e84-88.

30. Gould MK, Fletcher J, Iannettoni MD, et al. Evaluation of patients with pulmonary nodules: when is it lung cancer?: ACCP evidence-based clinical practice guidelines (2nd edition). Chest 2007;132(3 Suppl):108S-130S.

31. MacMahon H, Austin JH, Gamsu G, et al. Guidelines for management of small pulmonary nodules detected on CT scans: a statement from the Fleischner Society. Radiology 2005;237:395-400.

32. Blagev DP, Lloyd JF, Conner K, et al. Follow-up of incidental pulmonary nodules and the radiology report. J Am Coll Radiol 2014;11:378-383.

33. Lacson R, Prevedello LM, Andriole KP, et al. Factors associated with radiologists' adherence to Fleischner Society guidelines for management of pulmonary nodules. J Am Coll Radiol 2012;9:468-473.

34. Wiener RS, Gould MK, Slatore CG, et al. Resource use and guideline concordance in evaluation of pulmonary nodules for cancer: too much and too little care. JAMA Intern Med 2014;174:871-880.

35. Simos D, Hutton B, Clemons M. Are physicians choosing wisely when imaging for distant metastases in women with operable breast cancer? J Oncol Pract 2015;11:62-68.

36. Simos D, Hutton B, Graham ID, et al. Imaging for metastatic disease in patients with newly diagnosed breast cancer: are doctor's perceptions in keeping with the guidelines? J Eval Clin Pract 2015;21:67-73.

37. Cabana MD, Rand CS, Powe NR, et al. Why don't physicians follow clinical practice guidelines? A framework for improvement. JAMA 1999;282:1458-1465.

38. Simos D, Hutton B, Graham ID, et al. Patient perceptions and expectations regarding imaging for metastatic disease in early stage breast cancer. Springerplus 2014;3:176.

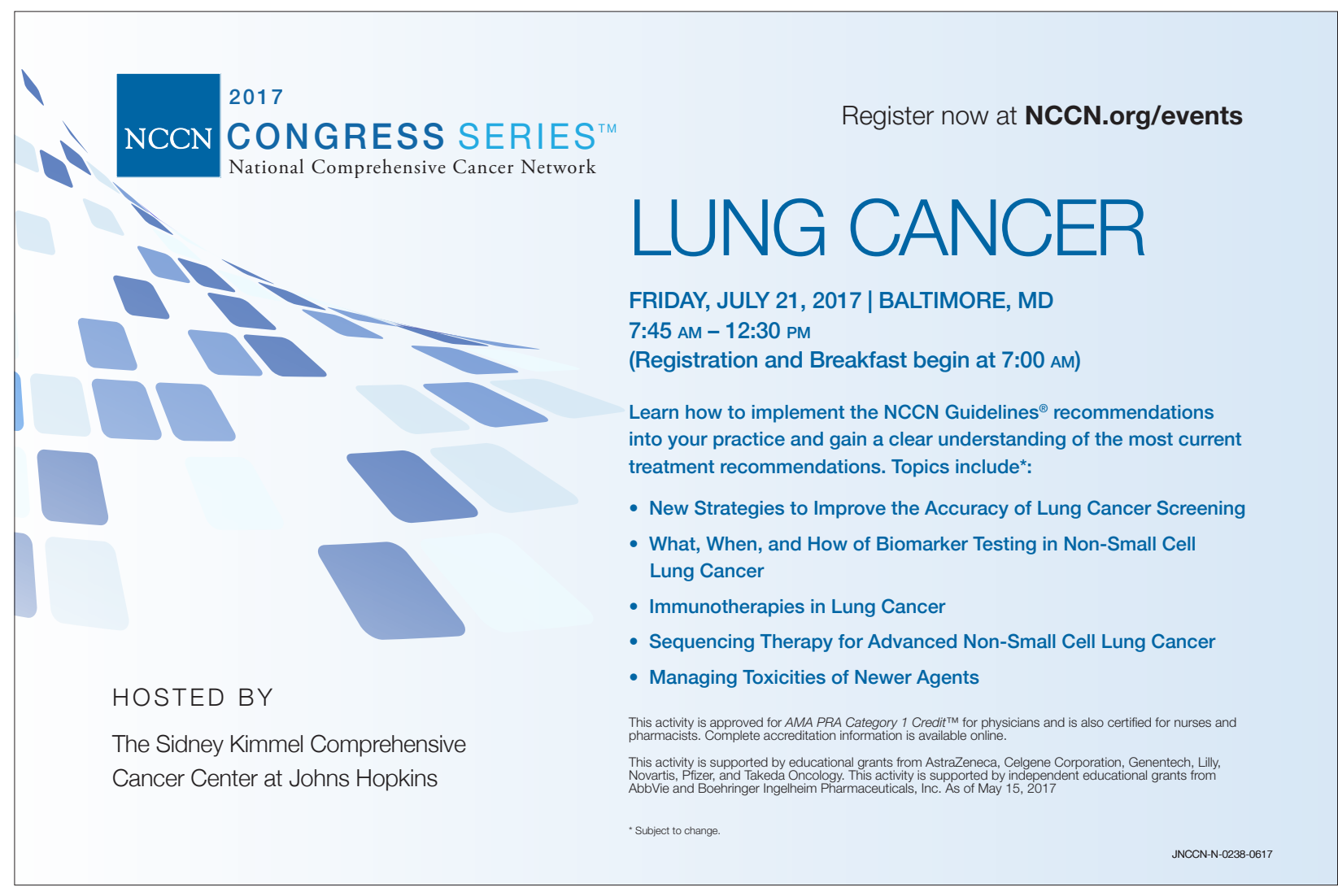

